\title{
O projeto do livro: Marcos Siscar, Manoel Ricardo de Lima, Sérgio Medeiros
}

Annita Costa Malufe

Pontifícia Universidade Católica de São Paulo

$\mathrm{H}$

á alguns livros de poemas, ou de narrativas breves, que parecem ter sido pensados, desde o início, como um todo. Conjunto mais ou menos coeso, mais ou menos calculado mas, em todo caso, um todo, constituído por partes que seriam cada um dos textos individuais. Livros que transparecem um projeto maior que envolveria sua feitura. Em casos ainda raros hoje, tem me chamado a atenção alguns livros que se dão como esse conjunto maior, como um grande ciclo, como se ele fosse por fim o "grande poema" ou o "romance" a ser lido. Pode ser que o projeto do livro tenha sido pensado no momento da redação dos textos individualmente ou não, que tenha sido um arranjo posterior - em cada caso talvez o processo seja diferente. Mas o que guiou meu mapeamento foi esta busca por livros que resultaram nesta espécie de conjunto mais orgânico ou coeso - ainda que essas palavras venham a se mostrar inadequadas nos casos escolhidos.

Como se conceber um todo que não seria propriamente um todo organizado, unificado, totalizável? Quando esses projetos de livro se destacam hoje - e refiro-me aos autores que aqui abordo, Marcos Siscar (1964, Borborema, SP), Manoel Ricardo de Lima (1970, Parnaíba, PI) e Sérgio Medeiros(1959, Bela Vista, MS) -, parece-me que isto se dá justamente por seus 
projetos negarem uma certa ideia de unidade ou coesão. $\mathrm{Ou}$ seja, eles nos dão a difícil tarefa de entender, ao mesmo tempo, a criação de um livro que é, por um lado, um todo mas, por outro, um todo que não é unificável, que se faz de fragmentos desencontrados, por rupturas, descontinuidades, lapsos. Falta-nos quase vocabulário para expressar a proposta que aí se dá. Queremos falar, ao que parece, de uma certa restituição da unidade: um livro que articula suas partes, que diz que elas pertencem a um mesmo conjunto. Mas ao mesmo tempo, talvez enxerguemos aí uma outra forma de unidade, não mais temática, não mais coesa.E queremos então falar de um todo que desfaz qualquer unificação. De partes que encontram um modo de estarem juntas sem se submeterem a elementos unificadores - que seriam, por exemplo, formais, temáticos ou da ordem da significação. O ponto em comum desses projetos de livro é portanto a ausência de um elemento unificador que garantiria a junção dos fragmentos de textos, o que os liga não é uma grande narrativa, explícita ou implícita, tampouco alguma significação mais certeira. Eles têm em comum a presença de uma narratividade que se dá a partir de fragmentos, uma narratividade sobretudo rítmica.

No início, parecia-me que toda esta problemática era mais pertinente em relação ao gênero poesia, no qual de fato é mais frequente livros que são reuniões de poemas independentes entre si, sendo mais raras as publicações que, rompendo com este modelo, se propõem a criar um conjunto em que os poemas se articulam entre si e se abrem uns aos outros. Mas, de certo, isto também poderia ser observado em relação a um livro de contos ou crônicas, em que é igualmente mais raro se ver a proposta de textos breves que não mais se bastam em si, mas se articulam no livro criando uma narrativa em fragmentos. No entanto, ao estudar esses livros projetados enquanto tal, nota-se que eles talvez proponham gêneros novos, que sua 
proposta já desfaça a própria noção de gênero; e de repente vemo-nos utilizando os termos prosa ou poesia não sem certo desconforto. Um livro como Totens, de Sérgio Medeiros, poderia ser considerado novo modo de romance, assim como As mãos, de Manoel Ricardo de Lima.

Estamos em uma linhagem que parece ter explodido com o romance, e mesmo a poesia ou o drama, se pensarmos no que se segue numa literatura como a de Samuel Beckett, em que pouco ou nada resta dos gêneros tradicionais. Em que a narrativa se faz de vozes em pedaços, articuladas e postas em continuidade por um ritmo. Em que pouco sobra das identidades dos personagens e da ação ou o enredo. Vale notar assim que a constituição desses livros fragmentários e, ao mesmo tempo, projetados, parece implicar frequentemente em uma revisão dos gêneros textuais, em uma indicação de que o "livro" pode se abrir a muitas possibilidades ainda inexploradas.

\section{Marcos Siscar}

Dentre as publicações da poesia brasileira, livros concebidos como um todo costumam ser mais raros. Talvez isto não seja um caso apenas da poesia contemporânea (e talvez não só a brasileira). É mais comum livros que são reuniões de poemas dispersos, reunidos enquanto textos independentes. Em geral temos coletâneas de poemas, que podem trazer uma maior ou menor coesão entre si, maior ou menor diversidade de tons, formas e/ou temáticas... Mas que são, em geral,compilação de poemas com bastante autonomia em relação uns aos outros. São mais raros livros como por exemplo o Livro do desassossego, esse projeto nunca concluído de Fernando Pessoa, livro escrito em fragmentos durante quase toda a sua vida. Este grande projeto de Pessoa que ficou inacabado, permanecendo em estado de projeto, inclusive, com alguns planos de como o livro seria 
futuramente ordenado. Em Pessoa temos ainda $O$ guardador de rebanhos, de Alberto Caeiro, outro livro projetado como um todo orgânico, arquitetado enquanto um grande ciclo de poemas numerados, inclusive. E ainda, Mensagem, de Fernando Pessoa ele mesmo, outro exemplo de livro de poemas articulados entre si, neste caso mais tematicamente, arranjando-se enquanto partes de um mesmo todo.

Entre nós, um caso exemplar seria o Poema sujo(1976), de Ferreira Gullar. Um livro composto por um único poema - ou melhor, um único poema que acabou compondo um livro. E no caso de Gullar não havia necessariamente um projeto de livro de antemão, mas o que acabou resultando foi um livro-poema único, composto de vários fragmentos. A resultante que temos é um livro que se dá enquanto um grande ciclo que articula ritmicamente esses fragmentos, que são bem heterogêneos entre si.

Neste mesmo sentido ainda, de um poema-livro, temos também o Galáxias (escrito no ano de publicação do Poema sujo, 1976), de Haroldo de Campos, grande "épico" contemporâneo, ou como ele dizia um "livro caleidoscópico" que traz um gesto épico, narrativo. São fragmentos, assim como no Poema sujo, mas neste caso articulados em um grande fluxo linguístico, ininterrupto, sem parágrafos, que cria novas continuidades entre fragmentos primeiramente soltos. O fluxo desfaz as quebras portanto e emenda pedaços em um mesmo jorro de palavras.

Dentre autores mais recentes, o paulista Marcos Siscar é um dos que se destacam nesta composição de livros projetados, que se apresentam enquanto corpos mais orgânicos, integrados. Em seu último livro, Interior via satélite (2010), Siscar criou um conjunto que pode ser visto como um grande ciclo, composto pelos poemas individuais. Ainda que sejam poemas independentes, eles se encontram articulados segundo uma 
rítmica interna - rítmica que se dá tanto em vista dos temas tratados, as imagens, paisagens e elementos recorrentes, quanto em vista da camada mais formal, métrica, visual e sonora.

Para criar esse ciclo maior do livro, um dos recursos utilizados por Siscar será, por exemplo, a retomada cíclica de elementos (frases, imagens, termos); ou seja, motes que retornam de tempos em tempos, enlaçando os poemas uns nos outros. "Pietà", por exemplo, é uma palavra e uma imagem que dá nome a três poemas diferentes, um em cada parte do livro (que tem quatro partes) e é citada também noutro poema ("Palavras gastas"). Outro exemplo: uma oração como "sem saber virar as páginas de um livro" ${ }^{1}$ aparece num poema no início e é retomada noutro contexto noutro poema mais adiante, desse modo: "você nem sabia virar as páginas de um livro". ${ }^{2}$ São procedimentos que Siscar utiliza para criar cruzamentos, cirandas entre poemas distintos, localizados em páginas distantes do livro, criando ciclos maiores que ligam poemas. Com isto ele remete o leitor a páginas anteriores e indica que esses poemas são como que fragmentos de um todo maior que é o conjunto deles no livro.

Interior via satélite marca significativamente a posição de Siscar da poesia enquanto trânsito entre os gêneros prosa e verso. Não há decisão quanto ao gênero do texto. E trata-se de um projeto consciente que Siscar vem empreendendo: de um livro a outro a mudança nítida na visualidade dos textos - de textos em "verso" (Metade da arte, de 2003), a textos em "prosa" (O roubo do silêncio, de 2006), nos sentidos correntes dos termos -, e depois essa oscilação de uma forma em perpétuo movimento e mise-en-forme, que veremos em Interior via-satélite. Uma forma em crise, para usar o conceito tão discutido por

\footnotetext{
${ }^{1}$ SISCAR, 2010a, p.17.

${ }^{2}$ SISCAR, 2010a, p.43.
} 
Marcos Siscar em seus artigos críticos, ${ }^{3}$ amplamente atentos à reflexão acerca do moderno e do contemporâneo. ${ }^{4}$ Forma esta não mais pensada em polaridade em relação a um conteúdo, mas repensada como uma "forma formante", para usar a expressão de Manoel Ricardo de Lima em estudo recentemente publicado. ${ }^{5}$

A poesia como uma pesquisa incessante dos modos de cesura, tons, manchas de texto, pontuação, brancos da página. Ao fazermos um voo panorâmico pelo livro de Siscar e observarmos seu relevo - para usar uma imagem frequente nos poemas: das texturas que se vê do alto do avião ou na foto de um satélite -, o que se sobressai é justamente o fator de heterogeneidade, um relevo irregular. Como nesses poemas que vimos aqui, há muita variação sintática, visual, de disposição do texto, das quebras de linhas e pontuação.Cada poema traz um modo diferente de experimentar o verso, as quebras e continuidades de linha; muitos são uma mescla com a prosa. Nossa leitura pode passar assim por essas oscilações de velocidade e entonação, essas variações das manchas de texto, das formas dos poemas. Há portanto uma continuidade rítmica que se cria na leitura, a partir dessas variações. Do que resulta um grande ciclo criado pelo conjunto do livro.

Essa oscilação é comparável àquela que temos em Poema sujo de Gullar, em que os fragmentos do poema estão dispostos criando um ritmo de passagem entre eles. Em ambos os casos,o que sobressai é uma nítida articulação interna, em que os poemas (em Siscar) ou fragmentos de poema (em Gullar) se encadeiam criando uma continuidade de variação

\footnotetext{
${ }^{3}$ Reunidos no livro Poesia e crise, de 2010.

4 Tratei em dois artigos recentes especificamente deste tema: "A poesia em crise ou a indecisão da forma" (Revista Fronteiraz, n. 8 e 9, 2012) e "Marcos Siscar e o verso em crise" (Revista Guavira, v.15, 2012).

${ }^{5}$ Cf. Lima, 2012a.
} 
rítmica. Espécie de narrativa do ritmo, de quebras e retomadas, momentos mais lentos e momentos acelerados, mais densos ou mais rarefeitos.

Há nesses livros, projetados enquanto um conjunto, uma quebra da unidade mais autônoma do poema. Pois eles são articulados de modo a se abrirem uns aos outros e, frequentemente, tornam-se fragmentos abertos e incompletos, ao invés de objetos fechados e acabados em si. $\mathrm{O}$ projeto de um livro contínuo, que sugere uma leitura que se dá entre os poemas individuais, parece acompanhar uma vontade de romper gêneros fixos. Como no Livro do desassossego de Pessoa, composto de fragmentos abertos que ecoam entre si. E, ainda, para lembrarmos de outro caso em Me segura que vou dar um troço (1972), de Waly Salomão: espécie de diário fragmentário, diário poético de ideias e jorro de palavras, concebido como livro único em que o gênero não seria nem poesia nem prosa exatamente. Haroldo de Campos é uma referência de Siscar, que cita trecho do Galáxias como uma das epígrafes do livro. Interessante pensar nos trânsitos entre gêneros que a composição do próprio livro de poesia acaba provocando. Como na fala de Haroldo: "Audiovideotexto, videotextogame, as galáxias se situam na fronteira entre prosa e poesia". ${ }^{6}$

\section{Manoel Ricardo de Lima}

Manoel Ricardo de Lima é outro autor atual que se empenha neste tipo de experimentação. O livro como corpo que articula fragmentos, livro sem gênero, forma, sem fixação possível. Há em seus escritos uma constante afirmação do hibridismo entre gêneros ou de sua indiscernibilidade. É o que acontece com mais força em seus livros As mãos (2003) e Jogo de

${ }^{6}$ CAMPOS, 2011, p.119. 
varetas (2012). É o que ele mesmo afirma acerca de sua escrita: "(...) nem poema nem prosa, nem prosa nem poema etc", em "Conversa", prólogo do autor que abre o livro mais recente Geografia aérea. ${ }^{7}$ No prefácio à reedição de As mãos, ele se refere a uma escolha por este lugar da incerteza dos gêneros, referindose a um: "desenho impreciso desse pequeno livro um limite entre o poema e a narrativa numa espécie de experiência móvel e desamparada". 8

As mãos é formado por textos curtos, de um ou dois parágrafos, duas páginas no máximo, e dividido em cinco partes numeradas por extenso, intituladas: um, dois, três, quatro, um, nesta ordem - sugerindo um retorno ao ponto inicial. Não somente no índice, a história supostamente narrada é descontínua, evita a linearidade. O leitor percebe uma história de amor que parece ter acabado e um personagem que relembraria, sozinho, detalhes dessa história, em uma atmosfera de angústia. Mas a incerteza quanto aos fatos e ao que pode ter se passado entre os dois personagens cria uma narrativa em constante suspensão. Apesar da linha contínua da frase, sem optar pelo corte do verso, essa linha é repleta de reticências, incompletudes, interrupções - intensificando o efeito de angústia. De modo que o silêncio vai pontuando cada uma das cenas, deixando no leitor uma espécie de enigma ou mistério constante - como no bilhete deixado pela mulher ao narrador:

O bilhete que ela me deixou escrito tinha umas frases numeradas, assim: 1] tanto. Logo em seguida, 2] não importa o nome da flor amarela e 3] tenho tentado arrastar o chão. Mais adiante, depois de um espaço: 6] talvez a flor e o amarelo. E por fim, 9]talvez um muro. O resto todo é ilegível, apagado ou não consigo dizer. ${ }^{9}$

\footnotetext{
${ }^{7}$ LIMA, 2014b, p.9.

${ }^{8}$ LIMA, 2012a, p.9.

${ }^{9}$ LIMA, 2012a, p.28.
} 
Os lapsos que pontuam a escrita parecem encarnar o embaçamento da memória e a dificuldade de dizer certas coisas. O livro se compõe assim de uma espécie de contra-narrativa, uma fuga do narrar da memória e da ação. A linha narrativa é antes imagética e, mais uma vez, rítmica. Uma narrativa poética que é um percurso por pequenos detalhes, ações muito pequenas, quase não-ações e muitas imagens em profusão, articuladas com o fluxo, entrecortado, da voz que narra.

Algo parecido compõe Jogo de varetas, mas nesse outro livro de Manoel Ricardo cada fragmento se refere a distintos personagens, que podem retornar de um fragmento a outro. Os textos também são breves, chegando a no máximo três páginas, e mais uma vez seu estatuto é híbrido, incerto. Não conceberíamos Jogo de varetas apenas como um livro de contos, assim como não conceberíamos As mãos apenas como uma novela ou romance. Há na constituição desses livros algo que pode nos levar a isto - o que contribui para a unidade do livro e, ao mesmo tempo, há a prosa desfeita, a sintaxe elíptica, a falsa narrativa, o destaque ao ritmo. Algo do que vemos por exemplo em uma prosa como a do irlandês Samuel Beckett, que muitos definem como prosa ou prosa poética, mas que é um tipo de texto híbrido por definição, mistura de poesia, drama e prosa. De modo que talvez a questão de gênero nem faça mais sentido a partir dessa experiência de Beckett.

Em relação aos personagens criados em Jogo de varetas, foi Sérgio Medeiros quem escreveu: “Dos 'beckettianos' brasileiros que eu conheço, Manoel Ricardo (...) é seguramente o autor mais bem-sucedido, entre os escritores da sua geração ${ }^{10} \cdot{ }^{10} \mathrm{~A}$ multiplicação de vozes e a significação frágil compõem marcadamente a poética de Manoel Ricardo de Lima, traços associáveis ao autor irlandês. Em Lima, os textos podem trazer uma primeira pessoa que enuncia, mas ela rapidamente é

${ }^{10}$ MEDEIROS, 2012a. 
cortada por outras vozes, intercalada, e a própria primazia da voz inicial é posta em xeque. De fato, alguma coisa que passa pelo estilo da prosa final de Beckett parece definir bem essas vozes sem identidade fixa, esses fluxos contínuos de palavras, os personagens sem rosto, quase-pessoas, ou não mais indivíduos. Alguma coisa parece se definir, ainda, no indefinível que marca o estilo beckettiano: nem poema nem prosa, nem prosa nem poema, nem teatro nem prosa nem poema... - prosseguiríamos a provocação de Manoel Ricardo de Lima.

Concordando com Sérgio Medeiros assim, Lima seria um de nossos "beckettianos", não só no seu trabalho com a indiscernibilidade dos gêneros mas ainda, pela presença dessas vozes entrecortadas, fluxo desenfreado de vozes que, por fim, se dão em fragmentos. Uma escrita que se faz entre fluxos de vozes anônimas, que fogem à fixação, e cortes frequentes que as fragmentam sem cessar. Poderíamos nos lembrar o quanto a prosa de Beckett começa a ser como que invadida pelas vozes de suas peças, como se a experiência com o teatro se infiltrasse na escrita desses textos não destinados aos palcos. É primeiramente em O inominável (1953), terceiro volume de sua trilogia romanesca da década de 1950, que a voz se torna por fim a personagem central. Voz que se descola dos corpos, das pessoas e se torna ela mesma um corpo sonoro, rítmico. Uma voz, segundo Blanchot, anônima, murmúrio incessante e sem rosto, fluxo de linguagem que carrega as mais diversas memórias e possíveis identidades. E então aí, diz ele: “Não se trata mais de personagens, sob a tranquilizadora proteção de seu nome pessoal, não se trata mais de uma narrativa, mesmo se conduzido no presente sem forma do monólogo interior" ${ }^{11}$

${ }^{11}$ BLANCHOT, 1959, p.289. 


\section{Sérgio Medeiros}

Devolvendo a Sérgio Medeiros a definição que emprega a Manoel Ricardo de Lima, encontraríamos em sua própria poética, aquela de Sérgio, traços que diríamos de uma proximidade forte com Beckett - tomando-o aqui mais uma vez como este marco de uma literatura da indefinição e do risco. A referência mais explicitamente declarada por Sérgio Medeiros é a da música de vanguarda, em especial John Cage e Olivier Messiaen. E, na literatura, James Joyce, escritor já homenageado por ele. Todas essas referências, e mesmo aquela do surrealismo às vezes associado à sua obra, não deixam de reforçar possíveis ressonâncias com a obra beckettiana.

Os livros de Sérgio Medeiros inventam um gênero único, que parece se inaugurar com o surgimento de cada um. Seus livros são em geral pensados enquanto tal, projetados enquanto livros, um ciclo inteiro, como se daria por exemplo a escrita de um romancista. Mesmo aqueles que se compõem de textos que obedecem mais estritamente a forma do poema, com o corte mais regular do verso, são pensados enquanto este grande ciclo que começa na primeira e termina na última página, como se fossem romances em versos, cada poema como parte de uma narrativa maior que os engloba. Mas não mais no sentido de um épico. E sim de uma narrativa quebrada, não unificável e não linear, de pequenas histórias sem importância - e muitas vezes sem sentido - e que não buscam síntese em uma grande narrativa.Seus personagens estão longe da definição tradicional aristotélica, não obedecem alguma verossimilhança, tampouco primam por uma interioridade ou pela representação de tipos sociais, conforme as exigências da tradição do romance burguês do século XIX.

Este trabalho de construção de personagens que pouco guardam de uma individualidade e nada teriam a ver com 
a representação de uma identidade (e muito menos com a garantia de uma verossimilhança da trama) é exemplar por exemplo na sua obra Figurantes (2011). Os poemas ou fragmentos aí trazem uma coleção de personagens insólitos, habitantes de uma ilha, que vai sendo mapeada no livro a partir desses seres da natureza que nela vivem. Esses textos breves são encadeados uns após os outros e seus títulos remetem a esses estranhos figurantes, numerando-os do primeiro - que se intitula "O primeiro a emergir" - até o "O centésimo nono". Não são109 poemas, porque alguns são apresentados em conjunto, como “O vigésimo quinto, o vigésimo sexto, o vigésimo sétimo e o vigésimo oitavo (mais a décima segunda)", e a partir daí os títulos começam a pular a ordem e brincar com essas aglomerações de personagens - com o que se intensifica o humor, que é uma das características do estilo de Sérgio Medeiros.

A ligação entre seus "figurantes" também não obedece uma lógica no livro, tampouco há um enredo que correria por debaixo. Trata-se antes de um jogo, montando um quebra-cabeça de peças disparatadas, que se encaixam por pertencerem a uma mesma história de absurdos sem lógica. Não sabemos se os personagens são insetos, animais, aves ou seres extraterrestres - mas tendemos mais a vê-los como insetos, uma diversidade de pequenos seres da natureza, enlaçando-se em troncos, raízes, molhando-se na chuva, no vento. Vejamos uns exemplos mais breves:
$O$ segundo
O segundo maneja duas pinças
Puxa folhas secas na grama
De repente ergue no ar uma pinça
Penetra um galho de árvore
Derruba folhas murchas
Ou colhe frutas maduras ${ }^{12}$

${ }^{12}$ MEDEIROS, 2011, p.16. 


\section{O décimo terceiro}

Um inseto voa entre os galhos

O traseiro imenso, como balão

O balão duro puxa-o para cima das copas

Ele olha para baixo

Sua cabeça é pequena, atada a órgão fino como um fio

Fixo no ar, o décimo terceiro, colosso precário, é de palha trançada Tem, porém, a face de ferro, voltada para baixo

Ameaça efetivamente quem passa por baixo ${ }^{13}$

\section{A centésima oitava e sua troupe}

O navio é como um boné branco

Que o vento virou para cima na água

A troupe embarca

\section{O centésimo nono}

No nevoeiro, ele adere ao morro

Ou se planta, repleto de espadas ${ }^{14}$

Tal como vemos aqui, a presença da natureza como uma espécie de protagonista é característica também de seus outros livros. Em Sexo vegetal (2009), Sérgio Medeiros explora elementos da natureza de modo muito singular, não mais uma natureza romântica e idealizada, mas uma natureza próxima e tátil, sensorial; modo de proximidade com o corpo e uma experiência erótica das palavras - o que ele brinca no prefácio de Totens (2012) ao dizer que a arte de sua personagem principal, o compositor português Enrique Flor (paródia com o pseudônimo do personagem Leopold Bloom de Ulisses de Joyce, Henry

\footnotetext{
${ }^{13}$ MEDEIROS, 2011, p.29.

${ }^{14}$ MEDEIROS, 2011, p.55.
} 
Flower), seria uma "arte vegetal", sendo tema do livro Totens o "sex appeal dos vegetais", termo que ele diz ter sido sugerido por Mario Perniola. ${ }^{15}$ Para o tema que aqui nos interessa, no caso desses dois livros de Sérgio Medeiros, Sexo vegetal e Totens, também o que encontramos é uma narrativa descontínua, criada com a justaposição de fragmentos breves, que intercalam diferentes modalidades de discurso e gêneros textuais.

\section{Fragmentação e não-senso}

O mapeamento desses projetos de livros parece apontar para dois modos diferentes de se escrever: um que leva em conta a grande forma, o grande ciclo do livro. E outro modo, mais frequente, que se concentra na pequena forma, na forma local, trabalhando cada texto como um objeto independente. Não se trata de um juízo de valor - há decerto livros bem ou mal sucedidos em ambas as modalidades -, mas da constatação de dois modos diferentes de se pensar tanto a composição do livro quanto a própria escrita dos textos. Nos casos em que aqui me detenho, é o livro que é a composição, e não cada texto em si. $\mathrm{E}$, nesses três casos, vemos que isto também não implica em se alcançar necessariamente uma coesão ou coerência do conjunto, não implica em criar um todo homogêneo, contínuo, harmônico.

Bem ao contrário, os três casos aqui escolhidos seriam exemplares de um outro modo de se entender e se buscar uma articulação do livro enquanto um todo que conjuga partes. Outros modelos de livro aí se mostram. Tem-se assim, uma restituição do contorno de conjunto que agregaria as partes de um livro e, ao mesmo tempo,tem-se composições fragmentárias, um todo que se mostra enquanto junção de fragmentos e que não busca uma unificação entre eles. Ou seja, nos casos de Siscar,

${ }^{15}$ MEDEIROS, 2012c, p.15. 
Lima e Medeiros, o livro - sua composição enquanto objeto total - não depende de que os fragmentos sejam submetidos a por exemplo, uma linha narrativa única e coerente, tampouco a uma significação que a todos abarque. Eles permanecem portanto enquanto tais: enquanto fragmentos, pedaços, estilhaços; e o todo que aí se faz é, por definição, fragmentário.

Em Siscar, Lima e Medeiros está-se diante de linhas poéticas distintas, que têm em comum a construção do livro como um corpo único e ao mesmo tempo não submetido a uma unidade de significado ou subjetivação. Os sujeitos aqui se multiplicam, e assim os significados e linhas bifurcantes das narrativas. Talvez não seja coincidência que as obras desses autores partilhem outro traço: o risco do não-senso, a escrita no limite da significação. Diria que Samuel Beckett surge como um marco para os três autores, por fim, e nos favorece a compreensão dessas propostas que rompem a narrativa tradicional - mas em um tipo de ruptura que se dá em especial a partir de forte investimento no não-senso.

Neste ponto, será preciso delimitar o que sugiro com este termo ao me referir a essas propostas, incluindo a de Beckett: não a falta de sentido, tampouco o nada ou o vazio de cunho existencialista. Mas,numa versão produtiva do conceito, a partir da formulação presente no pensamento de Deleuze, trata-se de sugerir o conceito de não-senso enquanto uma relação com os limites do sentido e, portanto, de sua própria possibilidade. ${ }^{16} \mathrm{~A}$ partir de Deleuze, podemos pensar o não-senso como um ponto de irrupção do sentido: "o não-senso opera uma doação de sentido", ${ }^{17}$ uma vez que o sentido é, na sua acepção, sempre a

\footnotetext{
${ }^{16}$ Opto por manter o hífen na grafia do termo, marcando que me refiro ao conceito específico trabalhado por Deleuze, em especial nas obras Lógica do sentido e Diferença e repetição, e salientando portanto a proximidade com o original francês (non-sense).

${ }^{17}$ DELEUZE, 1969, p.87.
} 
emergência de algo novo. A possibilidade do sentido coincide sempre com este ponto em branco, vazio de linguagem e significados prévios, que é o não-senso. Ou seja, não se trata de um não-senso enquanto "absurdo", apenas (ainda que o absurdo possa ser uma de suas figuras), mas sim, de um nãosenso constitutivo da linguagem em sua relação com os corpos. Vazio que não aponta para um esvaziamento mas, ao contrário, que é a própria condição para que o sentido possa emergir, enquanto algo sempre novo.

Seria preciso, portanto, especificar a força do não-senso em cada um dos autores - Lima, Siscar, Medeiros -, como a presença de um elemento insistente, que não permite o "fechamento" dos textos na camada da significação. No caso dos escritos dos três autores, o não-senso se insere muitas vezes entre os fragmentos do texto, como se viesse trazido pela quebra, abrupta, que se faz de diferentes modos em cada um dos três casos.O nãosenso pode ser uma espécie de lapso, cunhado entre as orações ou mesmo no meio delas. E tal lapso, ao romper a frase, tanto impede a conclusão da significação, quanto força a emergência de sentidos inesperados. É o não-senso portanto que pode impedir uma suposta unificação ou retorno da unidade em textos que trabalham com um outro modo de fragmentação: não mais os fragmentos que supõem uma totalidade (perdida ou a ser buscada como ápice ideal), mas fragmentos que compõem um todo quebradiço, que já não lamenta sua constituição fragmentária.

Em Sérgio Medeiros, o não-senso liga-se a maior parte das vezes ao efeito humor, que é um traço constante de sua escrita. Podemos nos lembrar que, além da importância de Joyce para sua literatura, Sérgio é bastante ligado ao nonsense da literatura de língua inglesa, como a de Lewis Carroll e Edward Lear. ${ }^{18}$ Daí esses personagens absurdos, que parecem saídos

18 Autor de Abook of nonsense (1846), livro ilustrado e escrito por Lear, que traz 
de uma tela surrealista ou de uma caricatura nonsense como as de Lear, e que, aqui muitas vezes, mal conseguimos visualizar. Esse humor presente em Medeiros seria associável ao tipo de humor encontrado em Beckett: humor no limite do nãosenso. Figurantes, por exemplo, é uma coleção de personagens insólitos, sujeitos que não encontrariam síntese em nossa visão mais acostumada, trazendo a definição impossível que uma linguagem baseada no não-senso poderia nos trazer. Daí ainda a dificuldade de recepção por parte do público que seus livros muitas vezes encontram, recepção comum diante de obras de caráter mais marcadamente "experimental". Propondo a interessante definição de "poesia transgênica" para o gênero textual híbrido de Medeiros, Maria Esther Maciel, sublinha essa experimentação presente no livro Totens de Medeiros:

(...) é um livro estranho, que resiste às classificações de gênero e desafia nossos esforços de compreensão. Isso graças ao seu caráter nonsense, conjugado a um experimentalismo radical e a uma complexa rede de referências literárias, musicais, plásticas e etnográficas. ${ }^{19}$

Como se vê, Maciel salienta a presença do não-senso em Medeiros, que, em seu caso, surge para desconsertar a linearidade lógica ou explicativa, tendo como efeito frequente o humor. Trata-se de um não-senso sem fundo, ou seja, que não aguarda uma decifração, uma explicação para nos fornecer o

poemas breves de humor nonsense, responsável por popularizar o gênero no século XIX, juntamente com Carroll. O conceito de nonsense - caro à literatura de língua inglesa, em Edward Lear e Lewis Carroll - é aqui utilizado em sentido mais amplo. Carroll é o autor privilegiado na obra de Deleuze Lógica do sentido, mas Deleuze avança em sua conceituação, fazendo do não-senso um conceito importante para reflexões acerca da linguagem (cf. DELEUZE, 1969). A diferença da grafia visa marcar também essas nuances (ver nota 16 acima). 19 MACIEL, 2012. 
sentido, para criar o efeito cômico. Daí sua singularidade, o tipo de riso descompromissado que ele pode sugerir. É também desta ordem o não-senso tal como vemos em Marcos Siscar: o lapso em sua escrita não possui uma resposta aguardando por detrás (ainda que no caso de Siscar o efeito não seja o humor). Isto significa que, como em Medeiros,em Siscar o lapso não é cunhado enquanto ocultamento de informações ou referências, a serem desvendadas para que o sentido se faça. Ele tampouco seria abarcável pela significação. No mais das vezes, trata-se de um vazio que também opera como este vácuo, que força a emergência de novos sentidos.

Próximo de outro modo ao que também Beckett trabalhou em sua literatura, em Siscar o texto frequentemente é imbuído de um fluxo vocal que muitas vezes engole os conceitos e faz do texto uma pequena partitura para falas múltiplas, uma significação em perpétuo deslize, desmanche. Os procedimentos de repetição e permutação de termos são aí frequentes e funcionam como modos de criar uma música da fala. Uma ciranda de hesitações e pausas diante daquilo que é dito. A fala muitas vezes é apenas "falar", ato sem destino certo, que parece ter o fim em si mesmo. Vale salientar que Siscar traduziu os poemas franceses de Beckett, aqueles publicados como Poèmes, suivi de mirlitonnades, dentre os quais figura o conhecido último poema escrito por Beckett, "Comment dire". Aqui, vemos quase em estado puro o procedimento que permeia os últimos textos de Beckett. Repetições e permutações de palavras em torno de um vazio a ser explorado enquanto única possibilidade da emergência de algo a se dizer - ainda que este algo seja, ele mesmo, o próprio vazio. O "Como dizer", na tradução de Siscar, inicia-se assim: 


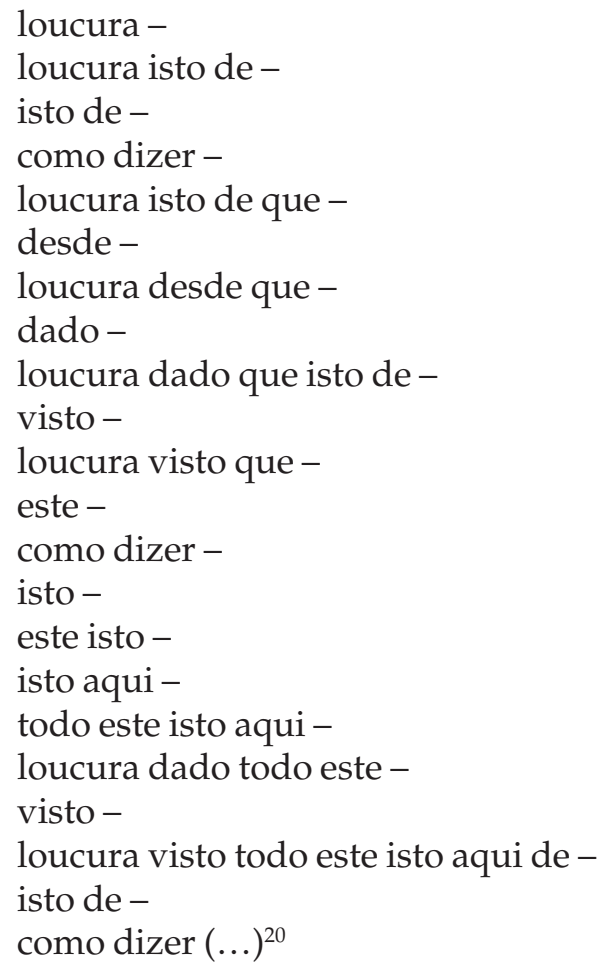

Talvez possamos afirmar que em Manoel Ricardo de Lima esse trabalho com o não-senso é de certo modo intensificado, uma vez que, com mais constância ainda do que em Siscar, ele se torna figura recorrente nas próprias operações sintáticas de seu texto. Há uma opção por uma escrita formada por lapsos e fissuras, que vão desencaixando a sintaxe comum.O fluxo rítmico e imagético do poema é criado com uma profusão de cortes, que suspendem o fechamento das orações:

\footnotetext{
${ }^{20}$ Marcos Siscar forneceu-me esta sua tradução do poema de Beckett, ainda inédita, para minha tese de doutorado - ela encontra-se publicada em Poéticas da imanência: Ana Cristina e Marcos Siscar (MALUFE, 2011, pp. 123-124).
} 


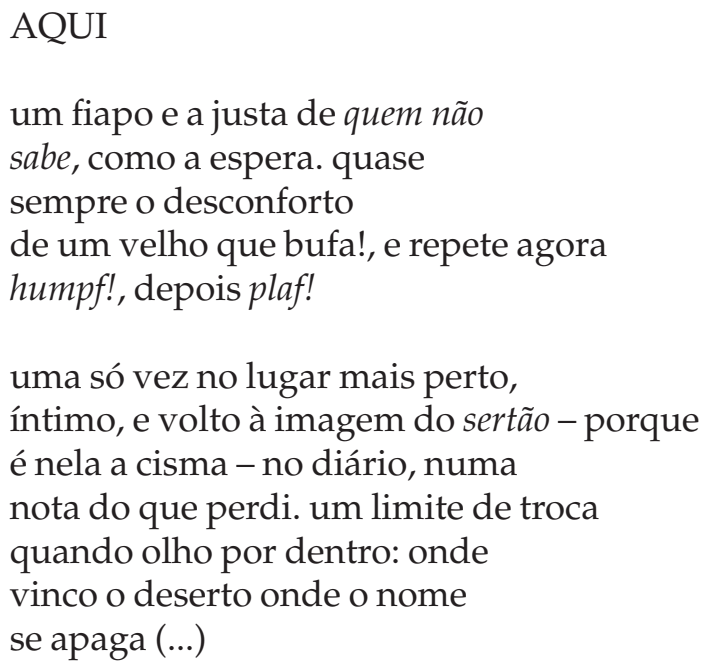

Uma suspensão dos significados acompanha a leitura. Por que o itálico nesta oração que se insere em meio ao primeiro verso "quem não sabe"? Onde se dá o tal "desconforto" a que se alude em seguida? Ele teria a ver com a "espera"? Há uma soltura entre os termos. Ler é portanto ir criando ligações que estão soltas, e ir, ainda, suportando a suspensão da camada do significado. Ao mesmo tempo, ler é ir seguindo esta linha quebrada, de um fluxo de cortes contínuos.Assim, temos em Manoel Ricardo de Lima um caso exemplar de uma sintaxe apoiada na fissura ou, para usarmos um termo que lhe é caro, no "acidente". Quando todos os acidentes acontecem é seu livro anterior a Geografia aérea, do qual muitos poemas - como o acima "Aqui" - foram reeditados para compor o novo conjunto. ${ }^{21}$

Tal operação de reescrita realizada por Manoel Ricardo faz-nos lembrar a de um outro autor também empenhado na composição do livro: o português Herberto Helder. Neste

${ }^{21}$ Livro para o qual escrevi o posfácio: "Perguntas e enigmas sem solução (percorrendo Geografia aérea, de Manoel Ricardo de Lima") (LIMA, 2004b, p.135-139). 
caso, um livro interminável, em reescritas sempre refeitas de seus próprios poemas. A reescrita é um modo de escrita em processo, em permanente projeto, sempre por se fazer e refazer. Um "poema contínuo", como diz Helder, continuamente reescrito. Da proposta de Helder, para o que nos interessa aqui, retenhamos uma ideia: a de um livro que flutua, que não se fixa, que sempre se projeta e se refaz. Um livro em movimento que, de algum modo, corrobora com novos modelos de livro, não mais cristalizáveis sob uma categoria como a de gênero. Que o livro e nem o texto sejam "definitivos", aí está um dos efeitos do trabalho radical com o não-senso, ao menos enquanto este ponto em branco e em suspenso, que abre o texto ao futuro das leituras. Fiquemos com a fala do escritor português:

As versões têm variado de destinatário para destinatário, não atendendo a qualquer conjunto de peculiaridades dos destinatários, mas porque o livro, em si mesmo, digamos, flutua. É um livro em suspensão, talvez só essa suspensão seja citável. Não é excitante que um livro não se cristalize, não seja 'definitivo'??2

22 HELDER, 1977. 


\section{Referências bibliográficas}

BECKETT, Samuel. L'Innommable. Paris : Minuit, 1953.

1991. . Cap au pire. Trad. Edith Fournier. Paris : Minuit, . Compagnie. Paris : Minuit, 1985. . Poèmes, suivi de Mirlitonnades.Paris : Minuit, 1978.

BLANCHOT, Maurice. Le Livre a venir. Paris: Gallimard/ Folio, 1959. CAMPOS, Haroldo de. Galáxias. São Paulo: Editora 34, 2011 (1ª edição 1984).

DELEUZE, Gilles. Critique et clinique. Paris : Minuit, 1993. . Différence et répétition. Paris : P.U.F., 1968. . “L'Épuisé". In: BECKETT, Samuel. Quad et autres pièces pour la télévision. Paris : Minuit, 1992. . Logique du sens. Paris : Minuit, 1969.

GULLAR, Ferreira. Poema sujo. In: Toda poesia (1950-1999). Rio de Janeiro: José Olympio, 2001 (1ª edição 1976).

HELDER, Herberto. "Carta a Eduardo Prado Coelho". Lisboa: Revista Abril no. 1, Outubro de 1977.

LIMA, Manoel Ricardo de. As mãos. Rio de Janeiro: 7Letras, 2012a.

Florianópolis: Ed. UFSC, 2014a.

. A forma-formante-ensaios com Joaquim Cardoso. . Geografia aérea. Rio de Janeiro: 7Letras, 2014b. . Jogo de varetas. Rio de Janeiro: 7Letras, 2012b.

MACIEL, Maria Esther. "A música da natureza na poesia de Sérgio Medeiros". In: Sérgio Medeiros, Blog Toten, 2012. Link: http:/ / medeirossergio.wordpress.com/2012/09/11/a-musica-da-naturezana-poesia-de-sergio-medeiros/\#more-99 (acesso em 01/04/2014). 
MALUFE, Annita Costa. Poéticas da imanência: Ana Cristina Cesar e Marcos Siscar. Rio de Janeiro/ São Paulo: Editora 7Letras e Fapesp, 2011.

MEDEIROS, Sérgio. "Alguns objetos dentro de uma sacola". In: Diário Catarinense, Caderno de Cultura. Florianópolis, 24/11/2012a.

. "Entrevista com Sérgio Medeiros, por Rodrigo de Souza Leão". In: Sérgio Medeiros, Blog Toten, 2012b. Link: http:/ / medeirossergio.wordpress.com (acesso em 01/04/2014).

. Figurantes. São Paulo: Iluminuras, 2011. . Sexo vegetal. São Paulo: Iluminuras, 2009. . Totens. São Paulo: Iluminuras, 2012c.

PAZ, Octavio. Los hijos del limo. Barcelona : Seix Barral, 1974.

PESSOA, Fernando. Livro do desassossego. Ed. Jerónimo Pizarro. Rio de Janeiro: Tinta-da-China, 2003.

SALOMÃO, Waly. Me segura qu'eu vou dar um troço. Rio de Janeiro: Aeroplano/ Biblioteca Nacional, 2003 (1a edição 1972).

SISCAR, Marcos. Interior via satélite. São Paulo: Ateliê Editorial, 2010a. Naify, 2003. . Metade da arte. Rio de Janeiro/São Paulo: 7Letras/Cosac . Poesia e crise. Campinas: Editora Unicamp, $2010 \mathrm{~b}$. . O roubo do silêncio. Rio de Janeiro: 7Letras, 2006. 


\section{RESUMO}

Dentre as publicações literárias realizadas hoje no Brasil, observa-se uma linhagem de autores que optam por livros planejados, ou seja, livros que não configuram coletâneas de textos independentes, mas que se apresentam enquanto conjuntos com certa coesão, em que os textos são como fragmentos de um todo maior que os une. Este artigo concentra-se na obra de alguns desses autores, como Marcos Siscar, Sérgio Medeiros e Manoel Ricardo de Lima, na busca por levantar pontos que nos levem a pensar decorrências de seus projetos poéticos. Pode-se dizer que esses autores realizam, cada um a seu modo, trânsitos entre os gêneros, dissolvendo fronteiras entre prosa, poesia e teatro, inserindo, assim, novos parâmetros para a leitura e propondo novos modelos de livro.

\section{RÉSUMÉ}

Parmi les publications littéraires réalisées aujourd'hui au Brésil, on voit un lignage d'auteurs dont les livres sont projetés comme des ensembles avec une certaine cohésion. C'est-à-dire, on y trouve une option pour la composition de livres qui, au lieu d'être des collections de poèmes indépendants, présentent un ensemble où les textes sont des fragments d'un tout plus vaste qui les réunie. Cet article s'occupe des œuvres decertains de ces auteurs, comme Marcos Siscar, Sérgio Medeiros e Manoel Ricardo de Lima, pour proposer des réflexions sur leurs projets poétiques. On peut dire que ces auteurs réalisent des croisements entre les genres littéraires et proposent des nouveaux modèles de livres, en incitent ainsi des nouveaux paramètres pour la lecture. 